\title{
AN ANALYTICAL APPROACH AGAINST PROGRESSIVE COLLAPSE AFTER EXPLOSION RC BUILDING
}

\author{
Murat ARAS ${ }^{* 1}$ 伲, Özlem ÇALIŞKAN ${ }^{2}$ \\ ${ }^{* 1}$ Res. Assistant of Civil Eng. Department, Bilecik Şeyh Edebali University, Bilecik, Turkey \\ ${ }^{2}$ Assistant Professor Dr. of Civil Eng. Department, Bilecik Şeyh Edebali University, Bilecik, Turkey
}

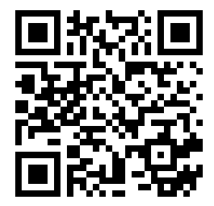

DOI: https://doi.org/10.29121/IJOEST.v4.i4.2020.97

Article Type: Research Article

Article Citation: Murat ARAS, and Özlem ÇALIȘKAN. (2020). AN ANALYTICAL APPROACH AGAINST PROGRESSIVE COLLAPSE AFTER EXPLOSION RC BUILDING.

International Journal of Engineering Science Technologies, 4(4), 1-10. https://doi.org/10.29121/IJOEST.v 4.i4.2020.97

Received Date: 05 July 2020

Accepted Date: 18 August 2020

Keywords:

Earthquake Engineering

Dynamics of Structures

Reinforced Concrete Buildings

Blast/ Impact/Shock

Design Codes

\begin{abstract}
Reinforced concrete structures may be subjected to uncontrolled sudden loads such as weight or rock fall, industrial or transport accidents, military or terrorist activities, controlled or bottled gas, natural gas, fuel tanker or fuel station explosion. It is difficult to predict how the structure will react under dynamic impact loading. However, creating scenarios taking measures against dynamic loading is a simple solution for behavior impact prediction. In this study was investigated to remove of the middle column in the reinforced concrete structure after the internal explosion. Static analyzes were carried out with IdeCAD Static software according to the load distributions after the carrier element removed in the typical building. In this study, load distribution principles are reviewed in accordance with ASCE 7-10, GSA 2016 and ACI 318 recommendations after subtracting elements. As a result, element remove scenarios are required as a design principle for structures.
\end{abstract}

\section{INTRODUCTION}

Reinforced concrete structures have to detailed static and dynamic loading scenarios, as well as industrial or transport accidents or military or terrorist activities due to accidental or deliberate impact or blasting loads (Figure 3). In addition, gas-filled tube, natural gas, fuel tanker or fuel station explosions can cause destructive reasons for buildings. It is usual for building elements to appear as detailing criteria in case of structural damage by shock as a result of weight drop, vehicle crash on vertical carrier elements or explosion. For this reason, both theoretical and experimental studies have been conducted on the behavior of structural elements subjected to impact loading from past to present.

Nowadays, preferred reinforced concrete structures are generally designed considering static, moving and dynamic loads such as earthquake/wind in project stage. Structural analysis generally not include the effects of sudden dynamic impact loads (Figure 1).

(C) 2020 The Author(s). This is an open access article distributed under the terms of the Creative Commons Attribution License, which permits unrestricted use, distribution, and reproduction in any medium, provided the original author and source are credited. 

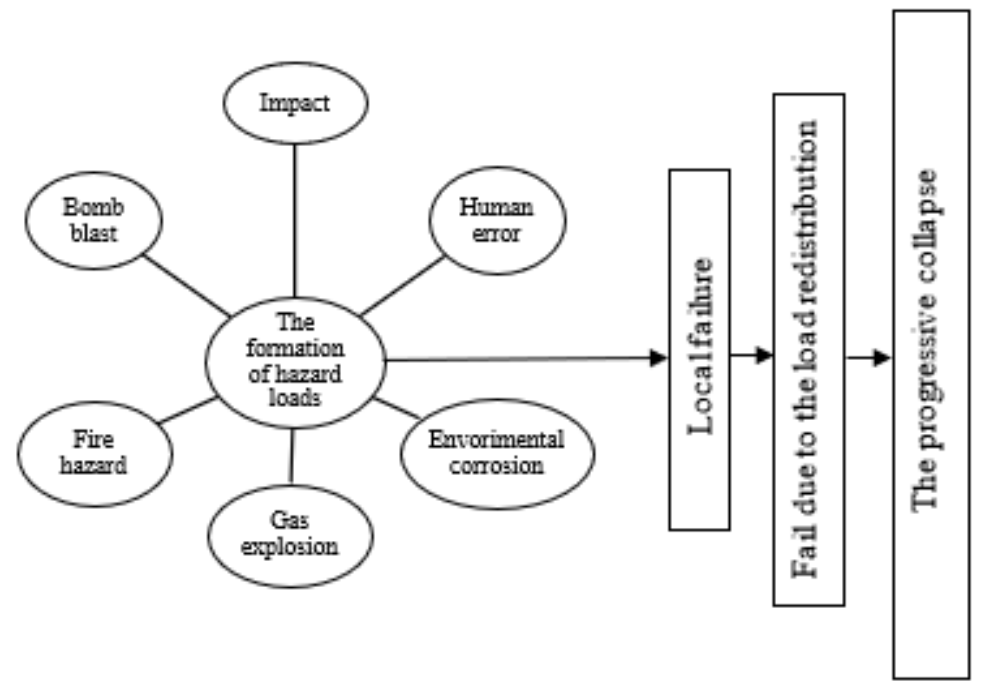

Figure 1: The process and engineering design measures of structural progressive collapse

The strategies for the design to resist different unexpected accidents are shown in Figure 2 according to EN1991-1-7.

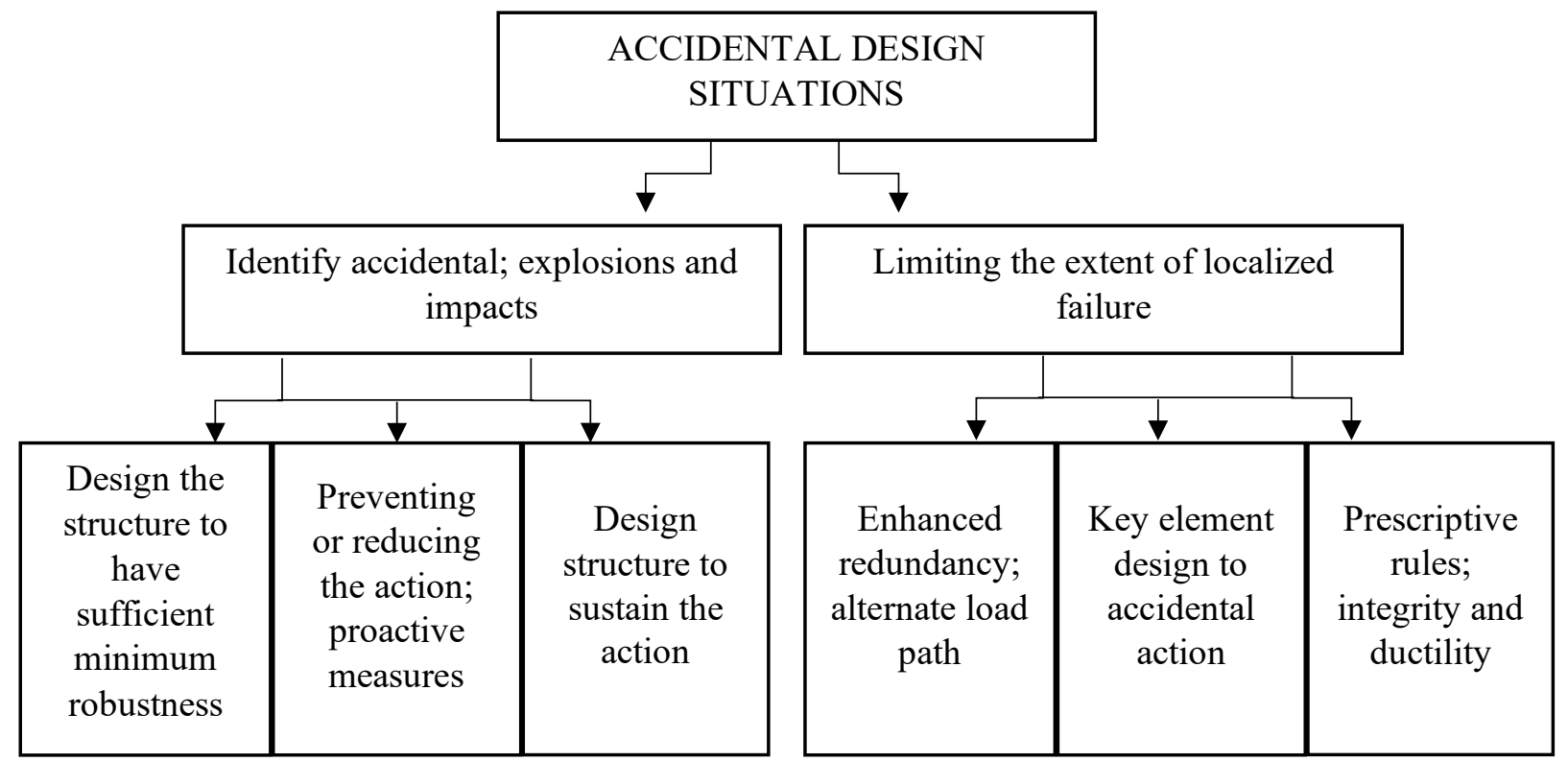

Figure 2: Different methodologies to resist accidental load actions (EN 1991-1-7, Eurocode 1: Actions on Structures - Part 1-7: General Actions - Accidental Actions, (2006))

The blast effects can be determined according to certain criteria. These effects can be divided into two main topics. The effects can be called ground shock and spherical shock wave respectively. The effect of ground shock is the impact of the explosion on the ground environment and the resulting acceleration. The effect of spherical shock wave can be expressed as the pressure wave created by the explosion in the air and this wave is called air shock. These effects are measured and taken into consideration during the design stage of the building to obtain the simulation of impact created by explosion on the structures. 

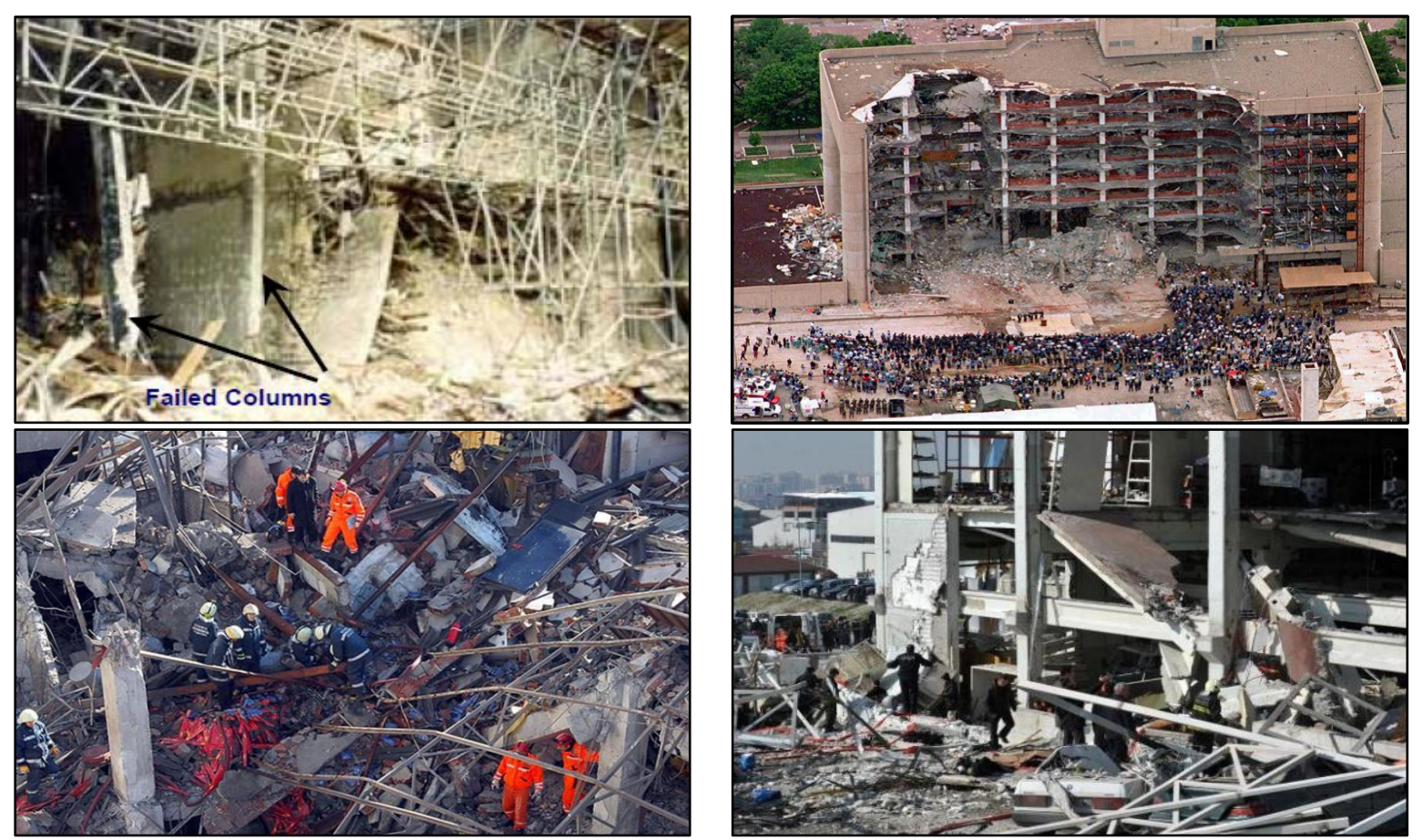

Figure 3: Kansallis House, City of London; Alfred P. Murrah Federal Building, Oklahoma, USA; Internal boast of the shop, Davutpaşa/İstanbul; Explosion of natural gas explosion, Ostim/Ankara

The blast wave that emerges after an explosion moves fast depending on the local pressure and temperature in an atmospheric. For this reason, the transition from high-pressure medium to low-pressure medium takes place very quickly after the explosion. The resulting high-pressure wave propagation, force, propagation time and velocity depend on the chemical reaction causing the explosion. However, the shock wave spreads and the moving air behind it expands and falls below atmospheric pressure with time [1]. The spherical shock wave, increase in pressure in the event of encounter an obstacle such as structure rapidly. Moreover pressure occurs in the case of an infinitely rigid and durable structure that prevents completely shock wave movement at the highest level. For example, the explosion will cause greater effects on condition that a closed ambient in the building [2], [3]. Internal explosions cause damaged to slabs and plastic hinge beams/columns in the structures. To emerge the pressure from shock wave no cause if the obstacle has a small area and the wave moves to free in the ambient [4].

In other words, the interaction of spherical shock waves and structures largely depends on the geometry of the structure and the properties of the wave ACI 318. It is very difficult to estimate different reflections due to complex geometries after the blast. Developed to the nowadays empirical formulas are not sufficient to evaluation of explosion effects and impulse parameters for different geometry building. For these reasons, experimental studies are required under dynamic effects for dynamic evaluation on structural elements. Impact load must be estimated against any obstacle in front of shock wave effects caused by explosion due to any explosion source. In addition, explosion may cause fatal lung damage or eardrum rupture. The most significant parameter in the explosion load is the characteristics of the source. Explosive sources may be LPG, natural gas or TNT due to terrorist attacks. It is very difficult to predict how the structure will react after the explosion.

However, pre-explosion collapse scenarios can be created how to getting precautions before explosion at structures. Structure occurs collapse when the structural element closest to the explosion mechanism is damaged. In the assumed explosion scenarios, it is necessary to identify local failure scenarios that may be caused by columns likely to be damaged. Thus, the prediction of the mechanism will be formed after plastic hinge. The most dangerous structures in these scenarios, they are less have column structures on the axle.

In recent years, researchers have been investigated using column loss tests analytical models real building structures in the dynamic load redistribution [5], [6], [7], [8], [9]. 


\subsection{BUILDING CODES AND GUIDELINES}

\subsubsection{ASCE 7-10}

The American Society of Civil Engineers Standard (ASCE 7-10) describes the mechanisms of sudden collapse in two main headings: direct and indirect design. Indirect approach provides solutions about redistribution after load carrying capacity of structural or structural elements to explosion case. Thus, minimum load values determined to alternative load distribution. Different structural elements may need to be used for structural ductility and strength. Load combination to determine the capacity of damaged structure after loss of carrier element;

$$
\begin{gathered}
\mathrm{G}_{\mathrm{ND}}=(0.9 \text { or } 1.2)+(0.5 L \text { or } 0.2 S), \\
\mathrm{L}_{\mathrm{LAT}}=0.002 \Sigma \mathrm{P}
\end{gathered}
$$

$\mathrm{G}_{\mathrm{ND}}=$ Gravity loads for nonlinear dynamic analysis

$\mathrm{D}=$ Dead load including façade loads $\left(\mathrm{lb} / \mathrm{ft}^{2}\right.$ or $\left.\mathrm{kN} / \mathrm{m}^{2}\right)$

$\mathrm{L}=$ Live load including live load reduction per ASCE $7\left(\mathrm{lb} / \mathrm{ft}^{2}\right.$ or $\left.\mathrm{kN} / \mathrm{m}^{2}\right)$

$\mathrm{S}=$ Snow load $\left(\mathrm{lb} / \mathrm{ft}^{2}\right.$ or $\left.\mathrm{kN} / \mathrm{m}^{2}\right)$

$\mathrm{L}_{\mathrm{LAT}}=$ Lateral load

$\Sigma \mathrm{P}=$ Sum of the gravity loads (Dead and Live) acting on only that floor; load increase factors are not employed

Load combination to evaluate the post-explosion strength capacity of the structural member;

$$
(0.9 \text { or } 1.2) D+1.0 A k+0.5 L+0.2 S
$$

$A_{k}$ : shows the load effect after the explosion.

Dynamic characteristic of progressive collapse is reflected by the loading procedure itself. Therefore, no dynamic increase factor is needed for NDP. Starting from zero, the loads defined in Equation 1 is applied to the entire structure including columns to be removed.

\subsubsection{ALTERNATE PATH METHOD (APM)}

This method widely is to recommended approach for advanced collapse system in building design. Linear, nonlinear and nonlinear dynamic procedures are three different. The Alternative Load Path method connected to GSA 2016, the structural element is removed on the column and applied loading procedures by Equation 3.

$$
\begin{aligned}
& G N=\Omega N(1.2 D+0.5 L) \\
& G=1.2 D+0.5 L
\end{aligned}
$$

Where, show $\Omega N$ : dynamic increase factor. As a result of linear static analysis, demand-capacity ratio of structural elements should be calculated in accordance with Equation 4. FEMA is determined as the request capacity ratio to calculate the inelastic behavior and request (DCR). DCR limit values are given in Table 1.

$$
\mathrm{DCR}=\mathrm{Q}_{\mathrm{UD}} / \mathrm{Q}_{\mathrm{CE}}
$$

Where, $\mathrm{Q}_{\mathrm{UD}}=$ Maximum bending moment after analysis, QCE: Structural strength, $\phi:$ Reduction coefficient.

Table 1: Summary of DCR limits

\begin{tabular}{|c|c|}
\hline Components / Action & Values for Liner Procedures \\
\cline { 2 - 2 } & DCR \\
\hline Beams-flexure & $2<\mathrm{DCR}<3$, depending on both flange and web slenderness \\
\hline Columns- flexure & \\
\hline For $0<\mathrm{P} / \mathrm{P}_{\mathrm{CL}}<0.5$ & $1.25<\mathrm{DCR}<2$, depending on both flange and web slenderness \\
\hline
\end{tabular}


Murat ARAS, and Özlem ÇALIŞKAN

\begin{tabular}{|c|c|}
\hline For $\mathrm{P} / \mathrm{P}_{\mathrm{CL}}>0.5$ & 1 \\
\hline Fully Restrained Moment Connections & 2 , for both Pre-and Post-Northridge \\
\hline Partially Restrained Moment Connections & 1.5 for tension failures \\
& 3 for flexural failures \\
\hline
\end{tabular}

In the AP analysis, case of greater than the three stories, a collapsed area must less than $70 \mathrm{~m}^{2}$ or 15 percent of total area the acceptable extent of damage for the removal of a wall or column on the external envelope of a building. The collapsed area of the floor directly above the removed element must be less than the smaller of $140 \mathrm{~m}^{2}$ or 30 percent of the total area in case of external structural element.

To summarize the prescriptions raised in the different design code guidelines, a comparison of load combinations for progressive collapse analysis in the different guidelines is also presented in Table 2.

Table 2: Load combination in different design code guidelines

\begin{tabular}{|c|c|}
\hline Code & Equation \\
\hline BS & $\mathrm{D}+\mathrm{L} / 3+\mathrm{W} / 3$ \\
\hline Eurocodes & $\mathrm{D}+\mathrm{A}_{\mathrm{d}}+\Psi \mathrm{Q}$ \\
\hline ASCE 7 & $(0.9$ or 1.2$) \mathrm{D}+(0.5 \mathrm{~L}$ or $\left.0.25 \mathrm{~S})+0.2 \mathrm{~W} ; 1.2 \mathrm{D}+\mathrm{A}_{\mathrm{k}}+0.2 \mathrm{~W}\right)$ \\
\hline GSA & $2(\mathrm{D}+0.25 \mathrm{~L})$ \\
\hline DoD & $2[(0.9$ or 1.2$) \mathrm{D}+(0.5 \mathrm{~L}$ or $0.2 \mathrm{~S})+0.2 \mathrm{~W}] ;(0.9$ or 1.2$) \mathrm{D}+(0.5 \mathrm{~L}$ or $0.2 \mathrm{~S})+0.2 \mathrm{~W}$ \\
\hline
\end{tabular}

The American Concrete Institute is trying to ensure the collapse of structural elements in reinforced concrete structures with the requirements of structural integrity. ACI 318-14 includes structural connection detailing for reinforced concrete structures.

\subsubsection{COLLAPSE ANALYSIS OF PROTOTYPE BUILDING}

Plastic hinge is mean yield rotation or unrecoverable rotation. Figure 4 illustrates the elastic and plastic rotation at the joint. The plastic hinge is associated with both the elastic and the plastic state, but the elastic case represents smaller dimensions.

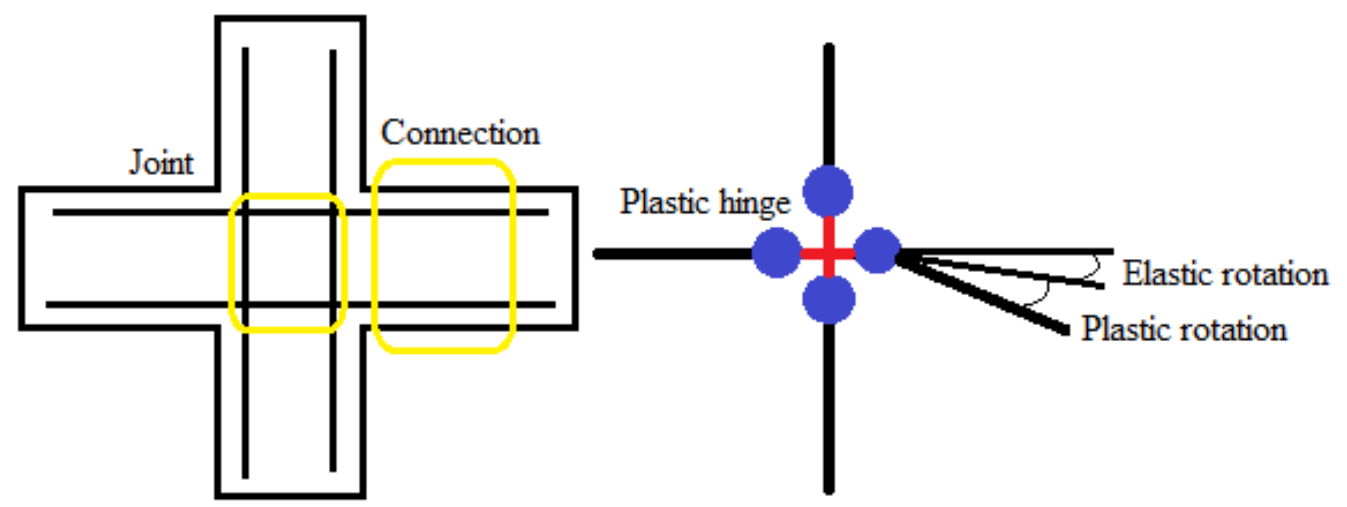

Figure 4: Node point detail

Nonlinear material behavior may be modeled to lumped plastic hinge to structural element. Lumped plasticity model is assumed to move expecting plastic hinges nonlinear plastic deformation along the whole element. Forcedeformation and moment curvature can be formed by using plastic hinge in the modeling. Column plastic hinge properties are generated using the values defined in ASCE 41-13 (Figure 5.a, b, c). Fig. 5 shows the momentcurvature relationship for columns as defined in ASCE 41-13.

My: yield moment, $\phi y$ : curvature, Mu: ultimate moment, $\phi u$ : ultimate curvature.

The parameters are given in the model given in Fig.5 according to the cross-sectional properties and shown Table 10-8 (ASCE 41-13). 


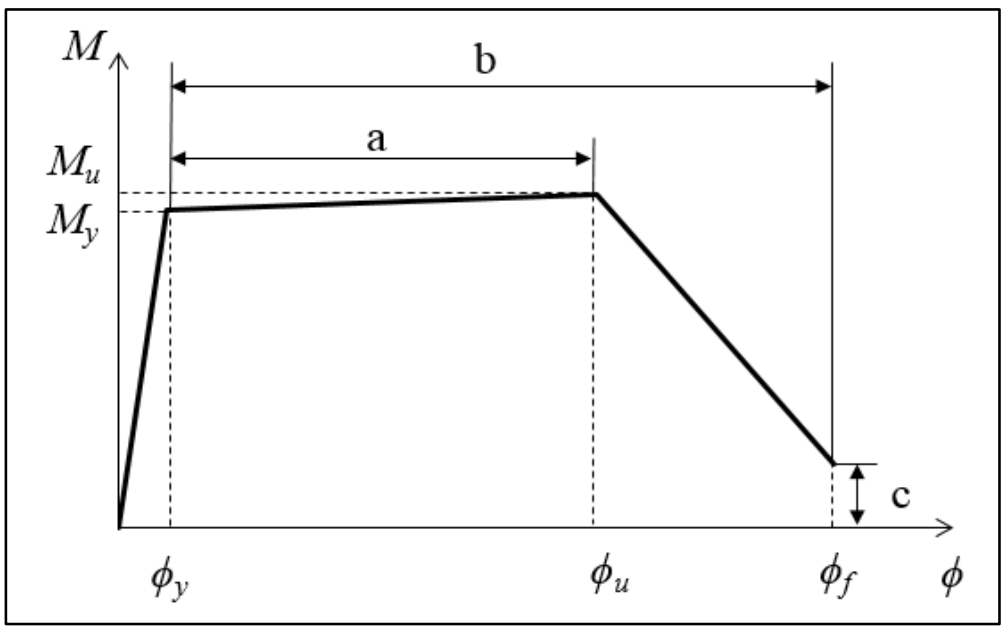

Figure 5: Backbone moment-curvature relationship for columns defined in ASCE 41-13

\section{ANALYTICAL MODEL}

In this study, static analysis was performed according to the load distribution that occurs after removal of elements after explosion in typical structures with reinforced concrete frames. The scope of the study, threedimensional models are created to determine internal forces, deformations and displacements in structures with 3 and 8 stories reinforced concrete frame structures. Beams-columns are one-dimensional and slabs have been adopted as rigid diagram each floor in their planes.

The column where middle center axles, removed as a scenario in the frame prototype model building. Figure 8 shows the plan and views of the reinforced concrete structure that is typically formed and model consists of 4 openings and $4 \mathrm{~m}$ spacing in $\mathrm{X}$ and $\mathrm{Y}$ directions. The cross-sectional dimensions of the vertical and horizontal elements were determined to be the same on whole floors, with beams 30x60 cm, columns $50 \times 50 \mathrm{~cm}$, slabs $15 \mathrm{~cm}$ and floor height $300 \mathrm{~cm}$. Mechanical properties of C25 concrete class and S420 reinforcement class in all models. The reinforced concrete structure is modeled to have $\mathrm{Z1}$ soil class and parameter of 1st earthquake zone for equivalent earthquake force. The total mass of the building is calculated by taking into account the total fixed load and $30 \%$ of the moving load. Rigid diagram is defined for each floor. One-way earthquake effect is used in models that neglected to vertical earthquake effect. The models were removed column of center axle and analyzed IdeCad software with load combinations according to ASCE 7-10 and GSA 2016 regulations (Figure 6).

\subsection{ANALYSIS RESULTS AND EVALUATION}

In this study, nonlinear static analyzes were performed according to the redistributed load after the element removed from the central axle. Model descriptions are given in Table 4.

Table 4: Model descriptions

\begin{tabular}{|c|c|}
\hline \multicolumn{2}{|c|}{ Model } \\
\hline M3 & 3 floor \\
\hline M8 & 8 floor \\
\hline M3-C & 3 floor removed column at center axle \\
\hline M8-C & 8 floor removed column at center axle \\
\hline M3-EC & 3 floor removed column at edge axle \\
\hline M8-EC & 8 floor removed column at edge axle \\
\hline
\end{tabular}

In the study, reinforced concrete problems occurred in neighboring axles, where the element was removed in M8-C and M8-EC prototype buildings. The problem is solved by adding punching reinforcement. Also, the column beam connection joint in ground and first floor was solved by increasing cross-section columns. 


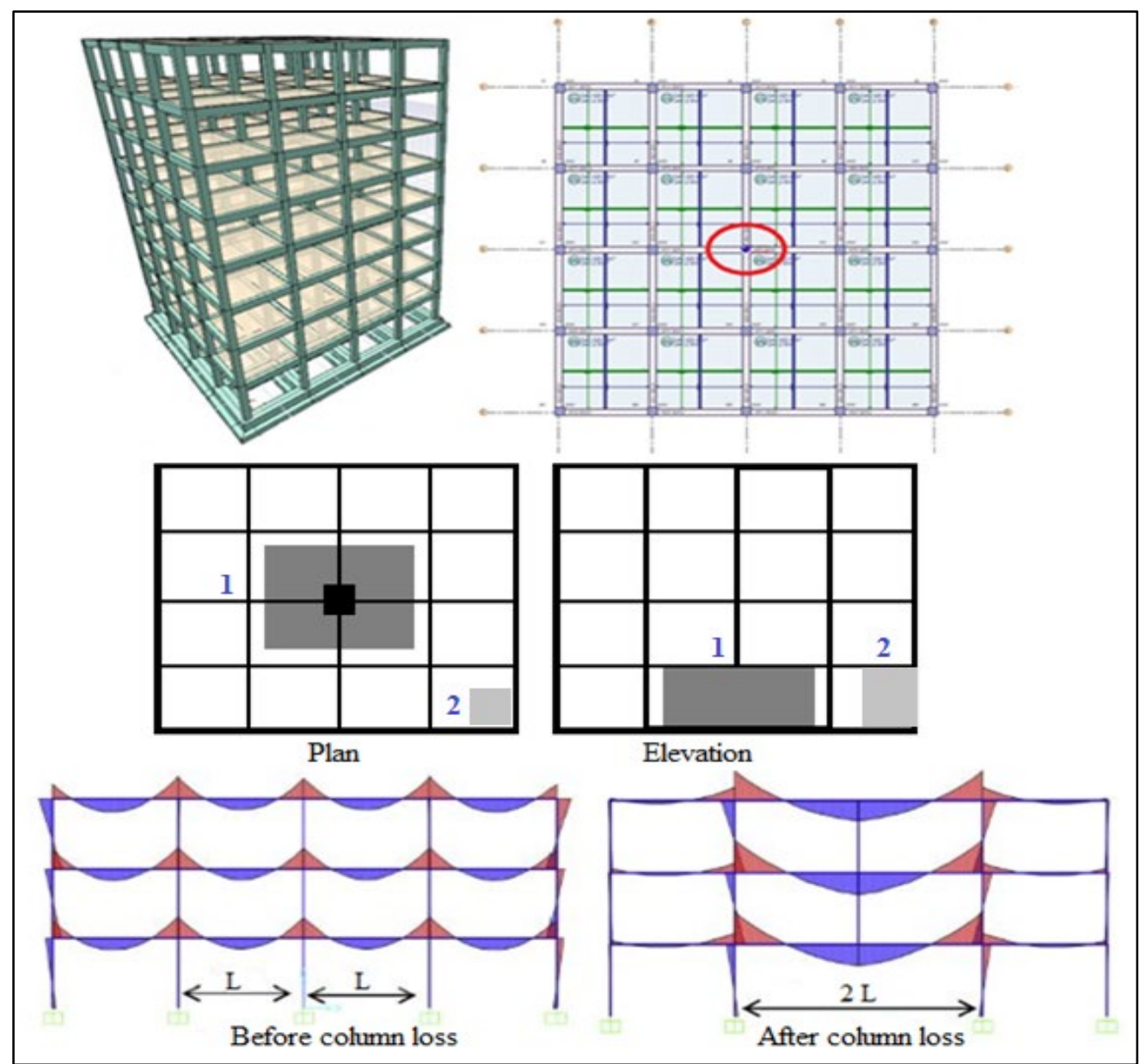

Figure 6: Prototype building

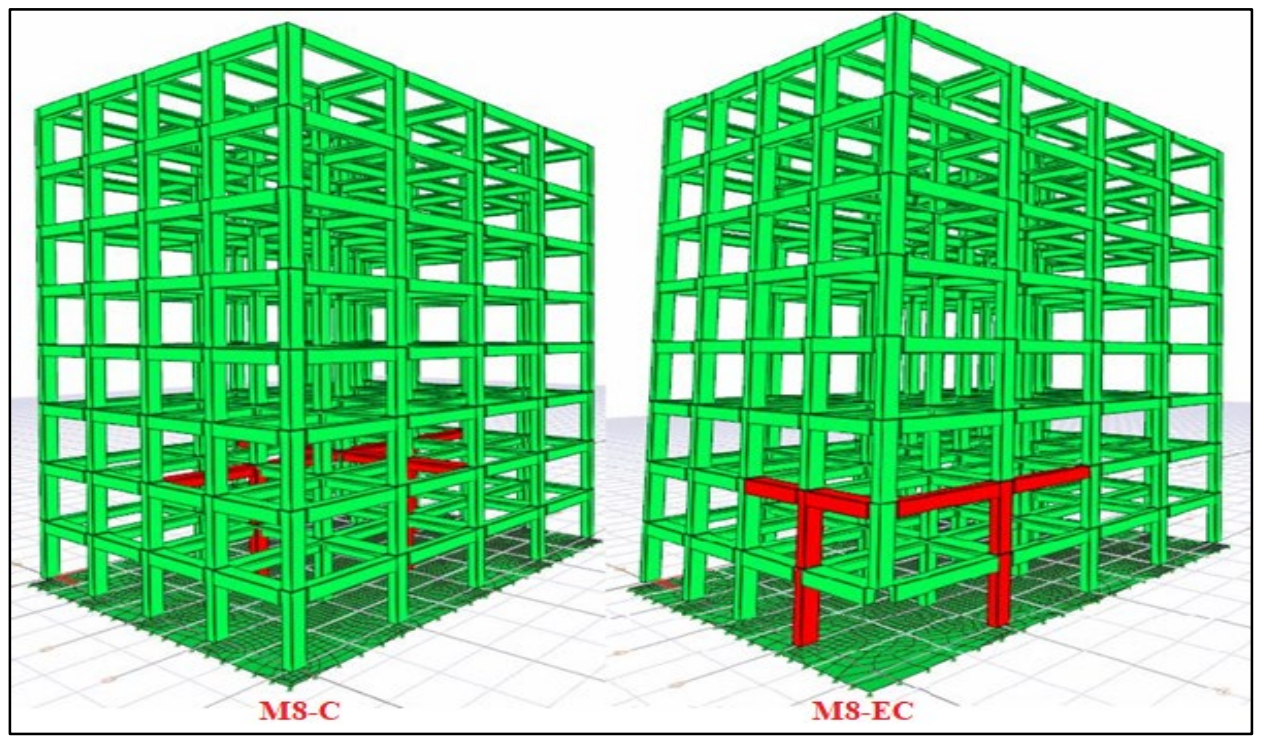

Figure 7: Reinforced Concrete Inadequacy in Structure (M8-C and M8-EC)

\subsection{MODAL ANALYSIS}

Modal analyzes were performed for each model according to the re-load distribution after subtraction of the element. Periods of the models are given in Figure 8. 


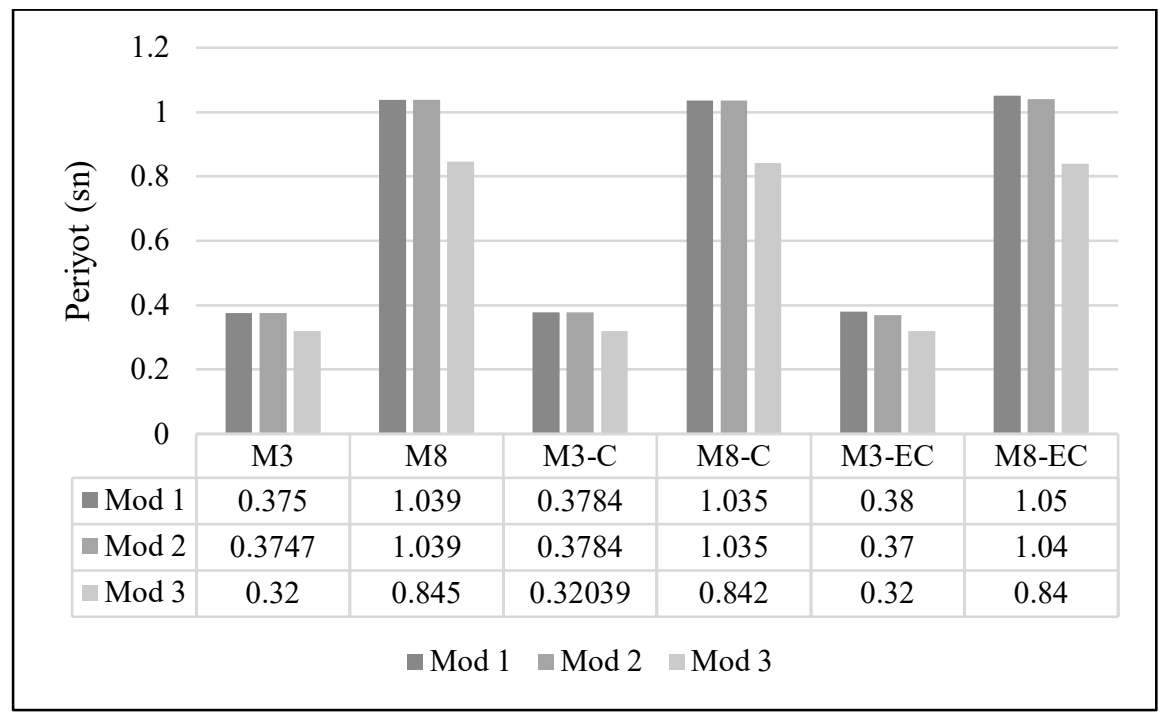

Figure 8: Building model periods

\subsection{MOMENT CAPACITIES}

The maximum moment capacity values are given in Figure 9 in the subtracted region for building models. The increase in moment capacity was approximately 3 times in the 3 and 8-storey model and approximately 6 times in the redistribution. After the redistribution, moment capacity increased the cross section of the design and reinforcement that secure design is provided for structural analysis. In the existing prototype models and elements with extracted models have been performed the criteria for earthquake general regulations. After the moment capacity increase, the reinforcement is provided by increasing the reinforcement from 12Ф14 to $16 \Phi 14$ in the axes that are equal distances to the central axle.

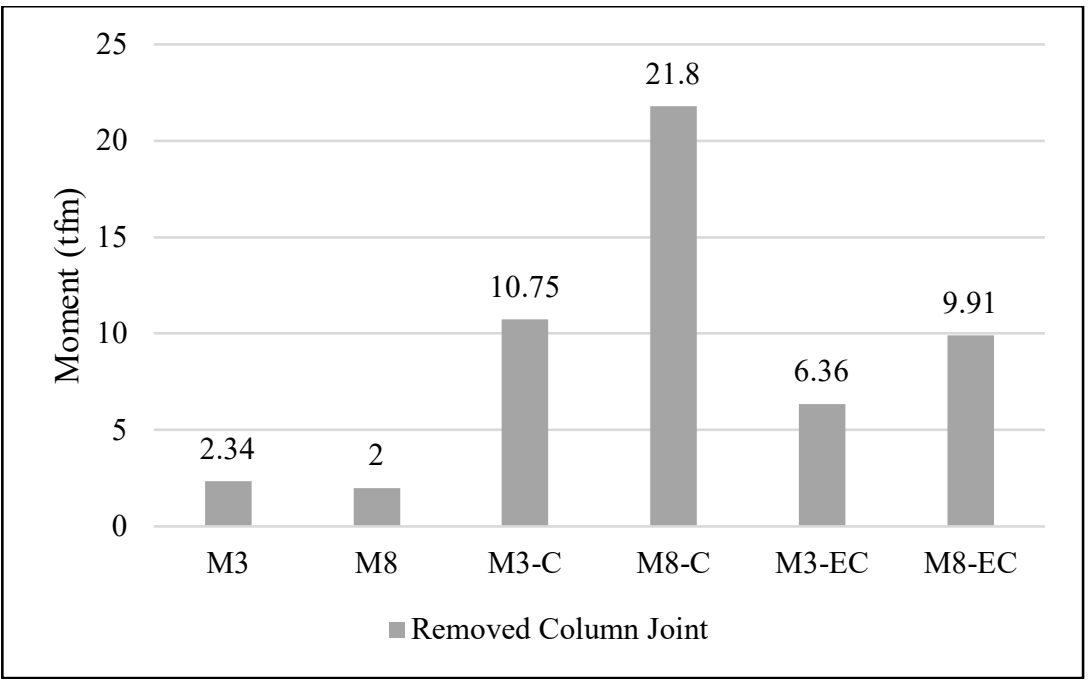

Figure 9: Moment capacity after column removed

\subsection{DISPLACEMENT OF REMOVED COLUMN JOINT}

Figure 10 shows the maximum displacement values in the removed column axle obtained from analyzes. Increases in displacement values occurred in the center axle where the column was removed. After the analysis according to the proposed load distribution, vertical displacement increases were observed. 
Murat ARAS, and Özlem ÇALIŞKAN

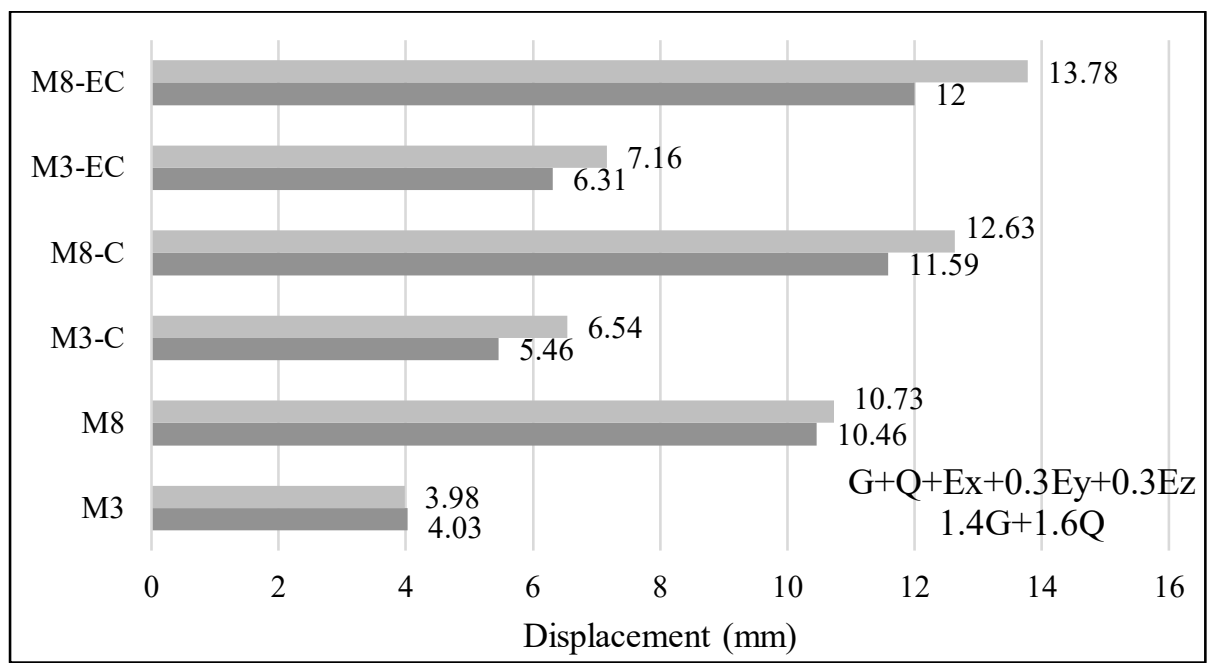

Figure 10: Maximum displacement values for scenarios

Figure 11 shows the maximum floor displacement values after obtained from different scenarios analyzes. Increases in displacement values occurred in the center axle where the column was removed. After the analysis according to the proposed load distribution, vertical displacement increases were observed.

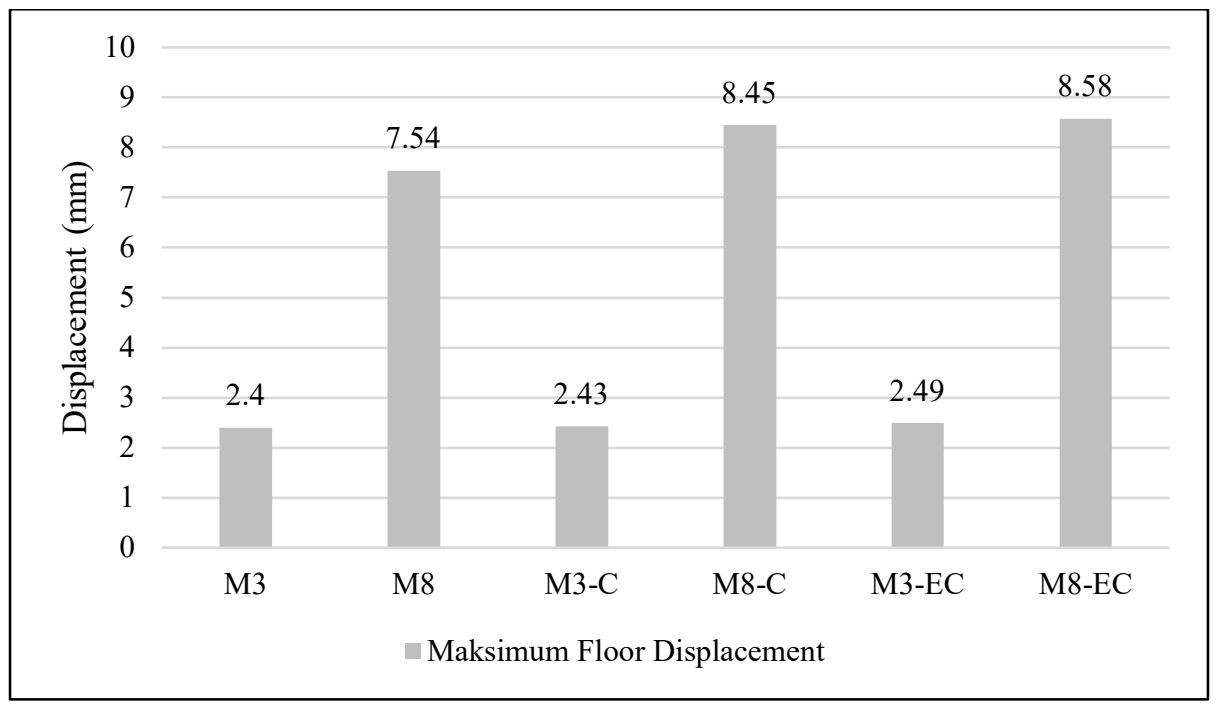

Figure 11: Maximum floor displacement values for scenarios

\section{CONCLUSION}

In this study indicated that there is no record for comprehensive information about the deterioration of explosion elements in the regulations on buildings to be constructed in earthquake zones in 2007 and 2019, TS 5002000 and TS 498-1997 regulations. This situation has caused a great uncertainty about how to take measures against the explosion effect of public and private structures in many parts of the world and our country. Controlled and uncontrolled explosion effects have been uncertainty on the structure. However, new load distribution may occurred after the creation of explosion scenarios for the solution and the reduction of the carrier element at the most critical point in the structural elements. In this study, the most critical carrier element in a 3 and 8 story symmetrical prototype structures and re-load distribution cases are examined. This study showed that, moment and displacement increases with ASCE 7-10 and GSA 2016 proposed re-load distribution after removed column. Thus, the structural models lead to increases in reinforcement, cross-sectional geometries and punching reinforcement. It has been seen that the formation of geometry of the sections by considering redistribution after a sudden load situation such as explosion in the structures. Thus, the design is considered according to the unfavorable situations. 
An Analytical Approach Against Progressive Collapse After Explosion RC Building

\section{SOURCES OF FUNDING}

This research received no specific grant from any funding agency in the public, commercial, or not-for-profit sectors.

\section{CONFLICT OF INTEREST}

The author have declared that no competing interests exist.

\section{ACKNOWLEDGMENT}

None.

\section{REFERENCES}

[1] G. Cullis (2001), "Blast Waves and How they Interact with Structures," Journal of the Royal Army Medical Corps, vol. 147, no. 1, pp. 16-26. https://doi.org/10.1136/jramc-147-01-02

[2] P. D. Smith and T. A. Rose (2002), "Blast Loading and Building Robustness", Progress in Structural Engineering and Materials, vol. 4, no. 2, pp. 213-223. https://doi.org/10.1002/pse.95

[3] R. A. Scott and L. J. Doemeny (1987), "Design Considerations for Toxic Chemical and Explosives Facilities", Washington, DC: American Chemical Society.

[4] P. D. Smith, T. A. Rose and E. Saotonglang (1999), "Clearing of Blast Waves from Building Facades," Proceedings of the ICE - Structures and Buildings, vol. 134, no. 2, pp. 193-199.

[5] Sasani M, Kazemi A, Sagiroglu S, Forest S (2011) Progressive collapse resistance of an actual 11-story structure subjected to severe initial damage. J Struct Eng 137(9):893-902. https://doi.org/10.1061/(ASCE)ST.1943-541X.0000418

[6] Qian K, Li B (2017) Dynamic and residual behavior of reinforced concrete floors following instantaneous removal of a column. Eng Struct 148:175-184. https://doi.org/10.1016/j.engstruct.2017.06. 059

[7] Chen J, Huang X, Ma R, He M (2012) Experimental study on the progressive collapse resistance of a two-story steel moment frame. J Perform Constr Facilit 26(5):567-575. https://doi.org/10. 1016/j.engstruct.2017.06.059

[8] Song BI, Sezen H (2013) Experimental and analytical progressive collapse assessment of a steel frame building. Eng Struct 56:664-672. https://doi.org/10.1016/j.engstruct.2013.05.050

[9] Xiao Y, Kunnath S, Li FW, Zhao YB, Lew HS, Bao Y (2015) Collapse test of three-story half-scale reinforced concrete frame building. ACI Struct J 112(4):429-438

[10] Liu C, Fung TC, Tan KH (2016) Dynamic performance of flush end-plate beam-column connections and design applications in progressive collapse. J Struct Eng 142(1):04015074-1-14. https:// doi.org/10.1061/(ASCE)ST.1943-541X.0001329

[11] American Concrete Institute (ACI). (2014). Building code requirements for structural concrete (ACI 318-14), ACI, Farmington Hills, MI, USA.

[12] TS 498, 1987, Design Loads for Buildings, Turkish Standards Institution, Turkey.

[13] TS 648, 1980, Building Code for Steel Structures, Turkish Standards Institution, Turkey.

[14] Turkish Earthquake Code (TEC), 2007, Principles for Buildings to be constructed on Earthquake Zones, The Ministry of Public Works and Settlement, Turkey.

[15] General Services Administration (GSA) (2003), Progressive collapse analysis and design guidelines for new federal office buildings and major modernization projects. Washington, DC: Office of Chief Architects. 